\author{
Rafael Knuesel \\ Stephan M. Jakob \\ Lukas Brander \\ Hendrik Bracht \\ Andreas Siegenthaler \\ Jukka Takala
}

\section{Changes in regional blood flow and $\mathrm{pCO}_{2}$ gradients during isolated abdominal aortic blood flow reduction}

Received: 7 October 2002

Accepted: 15 July 2003

Published online: 17 September 2003

(C) Springer-Verlag 2003

An editorial regarding this article can be found in the same issue (http://dx.doi.org/ 10.1007/s00134-003-2020-8)

This research was supported in part by grant 3200-061988 by the Swiss National Fund. The study was performed at the Surgical Research Unit, Department of Clinical Research and Clinic for Large Animals, University of Berne, Switzerland

R. Knuesel · S. M. Jakob (

L. Brander · H. Bracht - A. Siegenthaler J. Takala

Department of Intensive Care Medicine, Inselspital, University Hospital Berne, 3010 Berne, Switzerland e-mail: Stephan.Jakob@insel.ch Tel.: +41-31-6323916

Fax: +41-31-6329644

\begin{abstract}
Objective: $\mathrm{pCO}_{2}$ gradients are used for the assessment of splanchnic regional and local mucosal blood flow changes in experimental and clinical research. $\mathrm{pCO}_{2}$ gradients may not parallel blood flow changes because of concomitant changes in metabolism, hemoglobin, temperature, and the Haldane effect. Design and setting: A randomized, controlled animal experiment in a university experimental research laboratory. Interventions: An extracorporeal shunt with reservoir and roller pump was inserted between the proximal and the distal abdominal aorta in 16 pigs. In animals randomized to the low-flow group $(n=8)$ splanchnic perfusion was reduced by running the roller pump. At baseline and after 45 min of stable shunt flow superior mesenteric artery, celiac trunk, spleen artery, and portal vein blood flows and regional venous-arterial and jejunal and gastric mucos-
\end{abstract}

al-arterial $\mathrm{pCO}_{2}$ gradients were measured, and the respective regional $\mathrm{O}_{2}$ consumption rates $\left(\mathrm{VO}_{2}\right)$ calculated. Measurements and results: In the low-flow group all regional blood flows and the associated $\mathrm{VO}_{2}$ decreased to roughly $50 \%$ of baseline values, and hemoglobin decreased from 7.3 (4.4-9.6) $\mathrm{g} / \mathrm{dl}$ to 5.7 (4.1-8.9) g/dl. Decreasing regional blood flows were consistently associated with increasing regional and mucosal $\mathrm{pCO}_{2}$ gradients. Conclusions: During isolated reduction in abdominal aortic blood flow there is no preferential distribution to any splanchnic vascular bed and changes in regional $\mathrm{pCO}_{2}$ gradients reflect consistently the associated blood blow changes.

Keywords Low flow $\cdot$ Metabolism . $\mathrm{pCO}_{2}$ gradients $\cdot$ Regional blood flow $\cdot$ Splanchnic perfusion

\section{Introduction}

The gastrointestinal tract seems to be a major contributor to the pathogenesis of the systemic inflammatory response syndrome, sepsis, and multiple organ failure in critical illness $[1,2,3,4]$. The concept of an overproportional decrease in the perfusion of visceral organs in low-flow states to maintain central blood volume and cardiac output has been developed in earlier studies [5, $6,7,8,9]$. Hemodynamic variables and global parameters of tissue perfusion such as acid-base status, blood lactate concentration, and mixed venous oxygen satura- tion poorly reflect regional tissue perfusion $[10,11,12$, 13]. Monitoring of $\mathrm{CO}_{2}$ tension in the arterial and venous blood has been suggested for detection of poor regional and local tissue perfusion and oxygenation [14, $15,16,17]$. Under clinical conditions the direct determination of venous-arterial $\mathrm{pCO}_{2}$ gradients in the splanchnic vascular beds is not feasible. Intramucosal $\mathrm{pCO}_{2}$ can be measured indirectly within the lumen of the gastrointestinal tract by gastrointestinal tonometry [18]. However, the clinical utility of gastrointestinal tonometry remains controversial $[19,20,21]$, and studies that evaluate the correlation between the intramucosal $\mathrm{pH}$ (calcu- 
lated from intramucosal $\mathrm{pCO}_{2}$ using the modified Henderson-Hasselbalch equation [22, 23]) and splanchnic blood flow demonstrate inconsistencies [24].

The cellular $\mathrm{CO}_{2}$ level depends on the balance between (a) $\mathrm{CO}_{2}$ production via both aerobic and anaerobic metabolism and (b) $\mathrm{CO}_{2}$ removal by blood flow from the particular tissue bed and by alveolar ventilation from the systemic circulation [25]. The regional $\mathrm{CO}_{2}$ production is expressed as the product of the respective blood flow and the venous-arterial $\mathrm{CO}_{2}$ content difference. The rationale behind the use of mucosal-arterial (venous-arterial) $\mathrm{pCO}_{2}$ gradients as a measure of the adequacy of mucosal (regional) blood flow is the almost linear relationship between the blood carbon dioxide content and the corresponding $\mathrm{pCO}_{2}$ under stable conditions. However, there are potential confounding factors such as concomitant changes in hemoglobin, $\mathrm{pH}$, temperature, and the Haldane effect: increasing oxygen saturation increases the $\mathrm{pCO}_{2}$ for any given carbon dioxide content and vice versa [26]. Furthermore, changes in the local or regional $\mathrm{CO}_{2}$ content can occur as a result of phenomena entirely related to metabolism. Hence $\mathrm{pCO}_{2}$ gradients may not parallel blood flow changes.

Due to the complex anatomy and physiology of the splanchnic circulation and the limited access to these vascular beds in patients the interaction between changes in metabolism and blood flow and their effect on the measured regional and mucosal $\mathrm{pCO}_{2}$ gradients cannot be tested in the clinical setting. We therefore developed an experimental porcine model to selectively reduce the abdominal blood flow with limited systemic side effects. The aims of this study were the following: (a) to assess the regional blood flow distribution within the splanchnic circulation, (b) to compare regional perfusion, oxygen consumption, and $\mathrm{pCO}_{2}$ gradients during isolated reduction in visceral blood flow, and (c) to assess whether confounding factors such as changes in temperature, hemoglobin, and the Haldane effect affect the relationship between regional venous-arterial $\mathrm{pCO}_{2}$ gradients and blood flow in a low visceral perfusion state.

\section{Materials and methods}

Anesthesia and monitoring

This study was performed according to the National Institutes of Health guidelines for the use of experimental animals, and the protocol was approved by the Animal Care Committee of the Canton of Berne. Sixteen pigs of both genders (weight range 37-43 kg) were deprived of food but not water $24 \mathrm{~h}$ before the experiment. They were premedicated intramuscularly with $0.05 \mathrm{mg} / \mathrm{kg}$ atropine, $4 \mathrm{mg} / \mathrm{kg}$ xylacine, and $15 \mathrm{mg} / \mathrm{kg}$ ketamine followed by cannulation of an ear vein and intravenous administration of $5-10 \mathrm{mg} / \mathrm{kg}$ thiopental sodium for endotracheal intubation. As described previously, anesthesia was maintained with $5 \mathrm{mg} / \mathrm{kg}$ thiopental sodium and $30 \mu \mathrm{g} / \mathrm{kg}$ fentanyl per hour during the operation $[27,28]$. After completion of surgery the hourly fentanyl administration was reduced to $5 \mu \mathrm{g} / \mathrm{kg}$ and muscle relaxation with $1 \mathrm{mg} / \mathrm{kg}$ pancuronium per hour was started. The animals were mechanically ventilated with a volume-controlled ventilator (Servo 900C, Siemens, Solna, Sweden) with $5 \mathrm{cmH}_{2} \mathrm{O}$ end-expiratory pressure. Fractional inspired oxygen concentration was adjusted to keep $\mathrm{paO}_{2}$ levels between 100 and $150 \mathrm{mmHg}$. Tidal volume was kept at $10 \mathrm{ml} / \mathrm{kg}$ and the minute ventilation was adjusted to maintain $\mathrm{paCO}_{2}$ levels between 34 and $41 \mathrm{mmHg}$. A large-bore gastric tube was introduced into the stomach via the mouth. A right-sided carotid artery catheter, a pulmonary artery catheter (via the right submandibular vein), a catheter for later placement in a hepatic vein (via the right internal jugular vein,) and a right-sided femoral artery catheter were inserted. During surgery and the experiment the animals received per hour $10 \mathrm{ml} / \mathrm{kg}$ Ringer's lactate, $10 \mathrm{ml} / \mathrm{kg}$ gelatin solution (Physiogel), and $5 \mathrm{ml} / \mathrm{kg} 5 \%$ glucose. Additional fluid was administered if necessary to keep the pulmonary artery occluded pressure between 5 and $8 \mathrm{mmHg}$. The goal was to keep the body temperature of the animals at $39^{\circ} \pm 0.5^{\circ} \mathrm{C}$ by using an operating table heater, warmed fluids, and a blanket.

\section{Animal preparation}

The abdominal cavity was exposed by a midline abdominal incision. A drainage catheter was inserted into the urinary bladder. The superior mesenteric, splenic, hepatic, and femoral arteries, the celiac trunk, and the portal vein were exposed, and ultrasound transit time flow probes (Transonic Systems, Ithaca, N.Y., USA) were placed around the vessels. Two fluid-filled catheters were inserted proximally and distally into a mesenteric vein. The tip of the first catheter was placed into the portal vein, while the tip of the second catheter remained in the mesenteric vein. A third catheter was inserted into the splenic vein. The abdominal aorta was exposed through the left retroperitoneal space, and an ultrasound flow probe was placed around the aorta proximally to the origin of the celiac trunk. A $20-\mathrm{F}$ curved venous cardiopulmonary bypass cannula (Medtronic Cardiopulmonary, Anaheim, Calif., USA) was inserted into the abdominal aorta proximal to the aortic flow probe, and a second 20-F cannula was inserted into the distal aorta with the tip located proximal to the aortic bifurcation. The cannulas were connected to each other using silicon cardiopulmonary bypass tubes, a cardiotomy reservoir (Jostra, Irvine, Calif., USA) and a precision blood roller pump (Cobe, Denver, Colo., USA). A vascular occluder was placed around the aorta proximal to the distal cannula, and an aortic ultrasound flow probe was placed distal to the cannula (a schematic illustration of the shunt system is shown in Fig. 1). The pig received boli of 1000-2500 IU heparin to keep the activated clotting time at a level of $400 \mathrm{~s}$ minimum.

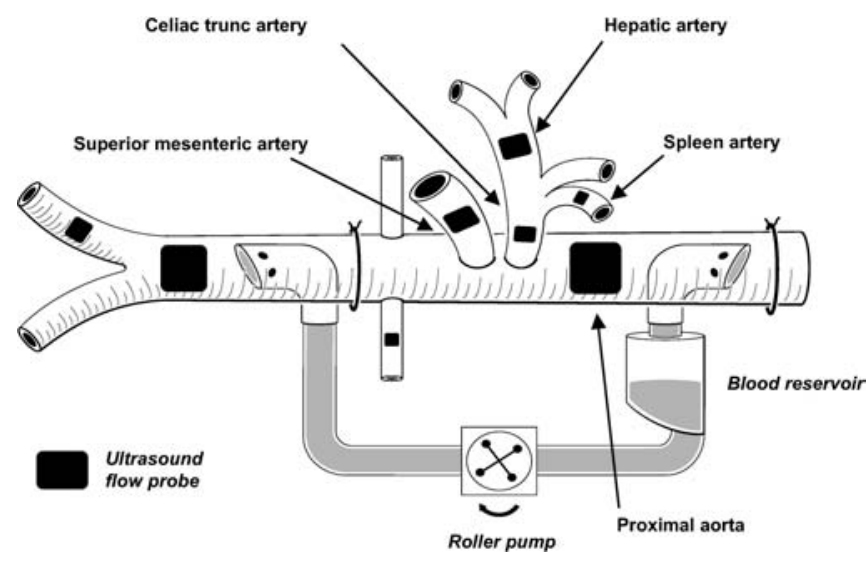

Fig. 1 Shunt system 
The measurements were performed using high-range activated clotting time cartridges (Medtronic, Minneapolis, Minn., USA) and an automatized activated clotting time analyzer (Medtronic HemoTec, Parker, Colo., USA). The catheter within the right internal jugular vein was further inserted and the location of the tip within a hepatic vein was confirmed by direct manual palpation. Thereafter the catheter was withdrawn $0.5-1 \mathrm{~cm}$ from the wedged position to allow blood sampling. A jejunal and a gastric air tonometry catheter (Tonometrics, TRIP NGS Catheter, Datex-Ohmeda, Helsinki, Finland) were inserted through an incision in the jejunal wall and orally, respectively, and connected to a Tonocap system (Datex-Ohmeda), after which the incision in the intestinal wall was closed with sutures. When all surgical procedures were completed, the abdominal wall was reapproximated gently, and towels were placed on the surface to minimize heat loss.

\section{Experimental protocol}

After preparation 180 min was allowed for hemodynamic stabilization before baseline measurements were made and samples were taken. The animals were randomized into two groups: a control group $(n=8)$ and a low-flow group $(n=8)$. In the low-flow group the distal abdominal aorta was occluded to prevent backflow from the distal cannula, and the abdominal aortic flow was reduced to a target total hepatosplanchnic blood flow (=celiac trunk + superior mesenteric arterial blood flow) of $50 \%$ of the baseline value by running the roller pump. Once the target abdominal aortic blood flow was reached, the shunt blood flow was kept constant for $45 \mathrm{~min}$. In four randomly allocated animals in the control group ("control/low shunt flow"), the shunt was activated with a low shunt flow of $250 \mathrm{ml} / \mathrm{min}$ to control for potential effects of the shunt per se. In the other four animals of the control group the shunt remained closed. At the end of the experiment the animals were killed by an overdose of intravenous potassium. Afterwards the correct position of the hepatic vein catheter was confirmed by anatomical dissection of the liver.

The protocol was carried out in 18 animals. Two animals were excluded post hoc because of discrepancies between size of aorta and aortic cannula with subsequent hypoperfusion of the legs in one animal and bleeding with severe anemia (baseline hemoglobin level less than $4 \mathrm{~g} / 100 \mathrm{ml}$ ) in another animal. Measurements after 45 min are labeled as "second measurement". There were no differences between groups in systemic hemodynamics and regional blood flow measurements at baseline. In one animal in the lowflow group the spleen flow probe was not properly working, and in one animal in the low-flow group and two in the control group it was not possible to obtain blood samples from the mesenteric vein. The corresponding results are therefore missing in the respective animals.

\section{Hemodynamic monitoring}

Aortic, carotid, pulmonary, and femoral arterial blood pressures, pulmonary artery occluded pressure, and central venous pressure were recorded with quartz pressure transducers and displayed continuously on a multimodular monitor and recorder (S/5 Critical Care Monitor, Datex-Ohmeda). All pressure transducers were simultaneously zeroed to the level of the heart. Cardiac output was measured by a thermodilution technique (mean value of four measurements). Central venous blood temperature was recorded from the thermistor in the pulmonary artery catheter. Heart rate was measured by electrocardiography, which was also continuously monitored.

\section{Blood flow measurements}

Abdominal aortic and regional blood flows were measured by ultrasound transit time flow probes (Transonic Systems). The transit time ultrasound volume flowmeter has been demonstrated to provide adequate measures of arterial and venous flows in experimental animals if carefully positioned and aligned with respect to the vessel $[29,30]$. The perivascular ultrasound flow probes were calibrated in vitro and the signals were visualized and recorded continuously (Flowmeters T108 and T208, Transonic Systems).

\section{Blood gas and lactate measurements}

Blood samples for the measurement of hemoglobin, blood gas analysis, and lactate were taken at baseline and after $45 \mathrm{~min}$ of stable shunt flow from carotid and pulmonary arteries and from portal, hepatic, mesenteric, and splenic veins and were analyzed immediately after withdrawal. Hemoglobin concentrations and oxygen saturations were measured by an analyzer designed for porcine blood (OSM 3, Radiometer, Copenhagen, Denmark), and lactate and blood gases were analyzed at $37^{\circ} \mathrm{C}$ in a blood gas, electrolyte and lactate analyzer (ABL 520, Radiometer).

\section{Calculations}

Systemic and regional venous-arterial carbon dioxide content differences were calculated using an iterative procedure as proposed by Giovannini and colleagues [31] (see Appendix). Since the accuracy of this method may be reduced if the metabolic acid-base status in venous and arterial blood largely differs [31], calculations at $45 \mathrm{~min}$ were performed only in control animals. The Haldane effect and changes in blood $\mathrm{pCO}_{2}$ mediated by changes in hemoglobin- $\mathrm{O}_{2}$ saturation and $\mathrm{O}_{2}$-linked $\mathrm{CO}_{2}$ binding was calculated as [32]:

$(\mathrm{v}-\mathrm{a}) \mathrm{pCO}_{2 \mathrm{HE}}=0.460\left[(\mathrm{a}-\mathrm{v}) \mathrm{HbO}_{2}\right]^{0.999} \mathrm{e}^{0.015}$ (pvCO2)-0.852 (Hct) Regional carbon dioxide production was calculated as the product of venous-arterial carbon dioxide content difference and regional blood flow. Regional oxygen consumption was calculated as the product of regional blood flow and arterial-venous oxygen content difference.

\section{Statistics}

Statistical analysis was performed with the SPSS software (version 10.0, SPSS, Chicago, Ill., USA). Because the number of animals per group was small, nonparametric tests were used. Visualization of blood flow and metabolic changes within controls and "control/low shunt flow" animals demonstrated no differences. These groups were therefore combined for the statistical analysis ("control group"). Groups at baseline were compared using the Mann-Whitney $U$ test; changes over time in each group were separately assessed by the Wilcoxon test. For the relative flow changes in the shunt group we used Friedman's test. Statistical significance was set at $p<0.05$. All results are presented as median (range) unless stated otherwise.

\section{Results}

Systemic hemodynamics and central temperature are shown in Table 1. At baseline there were no difference between the two groups. At the second measurement heart rate and cardiac output were increased in the control group while mean arterial pressure did not change in 
Table 1 Hemodynamics, temperature, arterial blood gas measurements, and hemoglobin

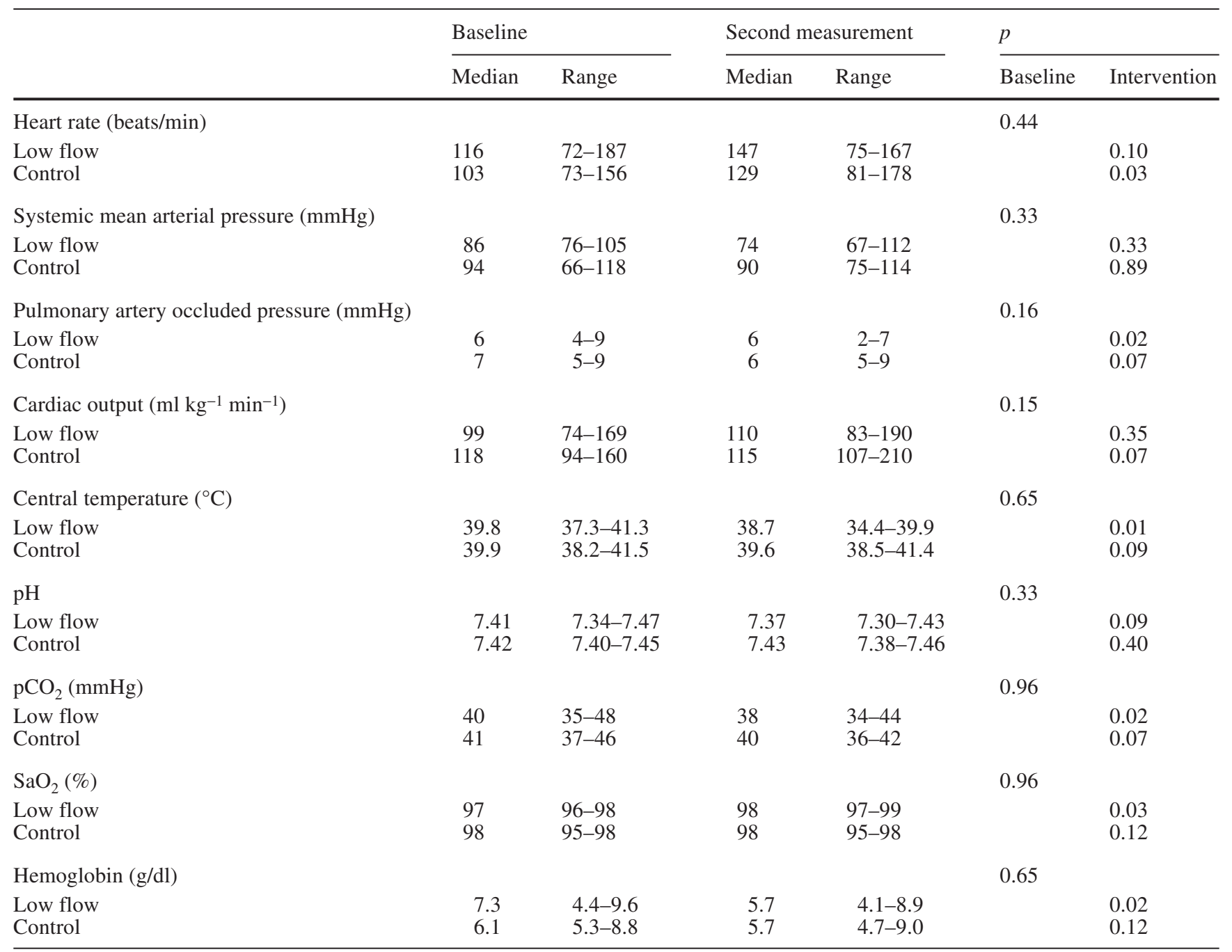

either group. In the low-flow group wedge pressure was decreased. Blood gas measurements and hemoglobin values are also shown in Table 1 . Arterial $\mathrm{pCO}_{2}$ and hemoglobin were decreased in the low-flow group, but remained unchanged in controls. Aortic and regional blood flows are shown in Table 2. Aortic and regional blood flows did not differ at baseline, and changes in controls were not significant. In the low-flow group abdominal aortic and all regional blood flows were decreased by $50 \%-80 \%$. The relative flow changes did not differ in the individual vascular beds $(p=0.45)$. There were no differences in blood lactate concentrations at baseline between animals in the two groups (Table 3). Lactate concentrations increased in the venous effluents of all vascular beds in animals from the low-flow group.

The regional venous-arterial $\mathrm{pCO}_{2}$-gradients did not differ between groups at baseline (Table 4). In the low- flow group the splenic, mesenteric, and portal venousarterial $\mathrm{pCO}_{2}$ gradient was increased. In the control group overall venous-arterial $\mathrm{CO}_{2}$ content differences remained unchanged. In general, small changes in $\mathrm{CO}_{2}$ content differences corresponded well with the respective changes in $\mathrm{pCO}_{2}$ differences (Fig. 2). Gastric and jejunal tonometric values, although highly variable in both groups, were increased in low flow animals (Table 4). Changes in blood $\mathrm{pCO}_{2}$ mediated by changes in $\mathrm{Hb}-\mathrm{O} 2$ saturation and $\mathrm{O} 2$-linked $\mathrm{CO}_{2}$ binding provided a mean regional ( $\mathrm{v}-\mathrm{a}) \mathrm{pCO}_{2} \mathrm{HE}$ value of $4 \mathrm{mmHg}$ (all animals and conditions). During low flow, values of up to $10 \mathrm{mmHg}$ were obtained. The relative contribution to the measured regional $\mathrm{pCO}_{2}$ gradients was $23 \%-48 \%$, depending on the respective region. Results for regional oxygen consumption $\left(\mathrm{VO}_{2}\right)$ and oxygen extraction rates are shown in Table 5. Hepatic oxygen consumption was 
Table 2 Aortic and regional blood flows

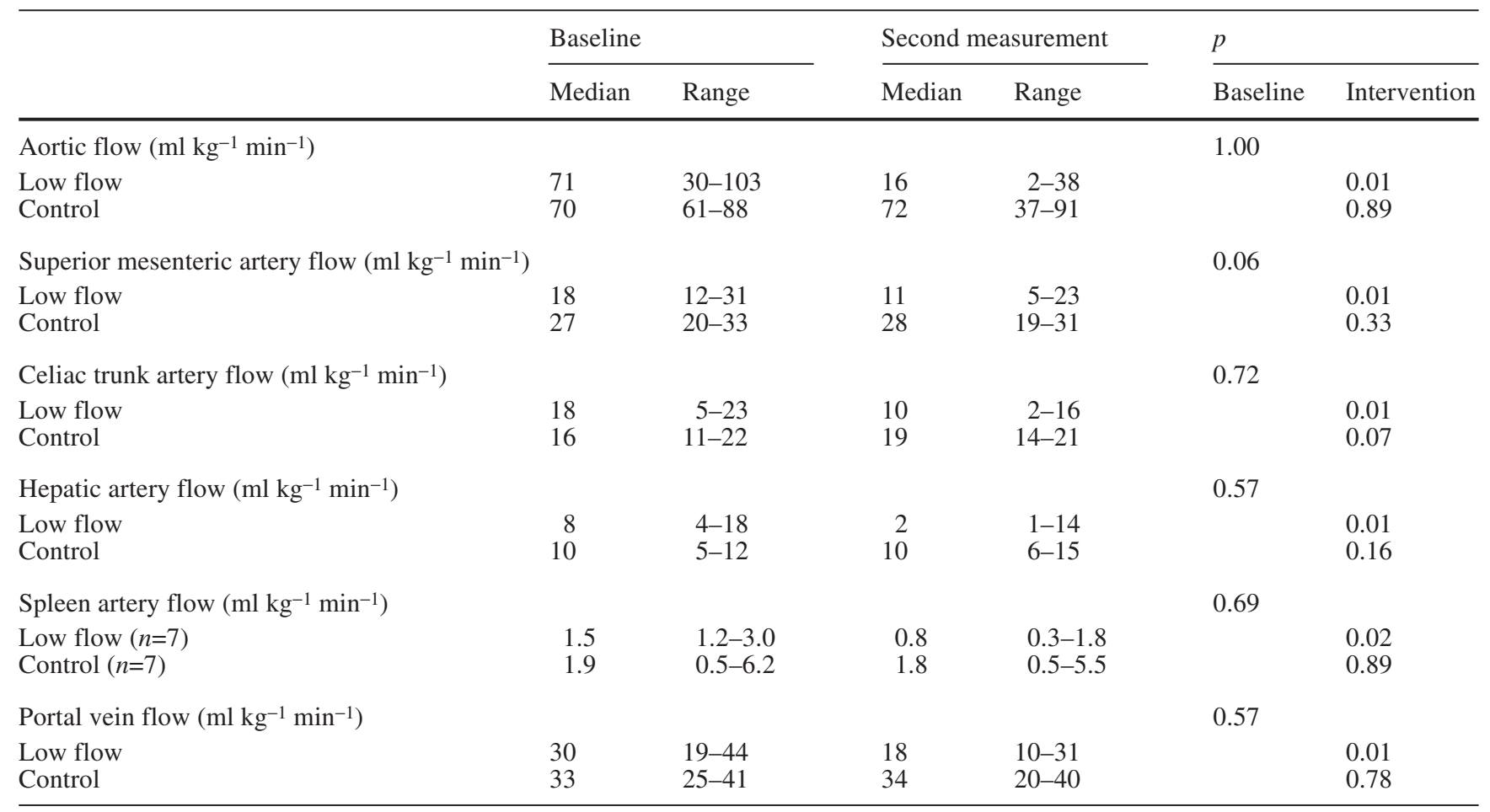

Table 3 Systemic arterial and regional venous lactate

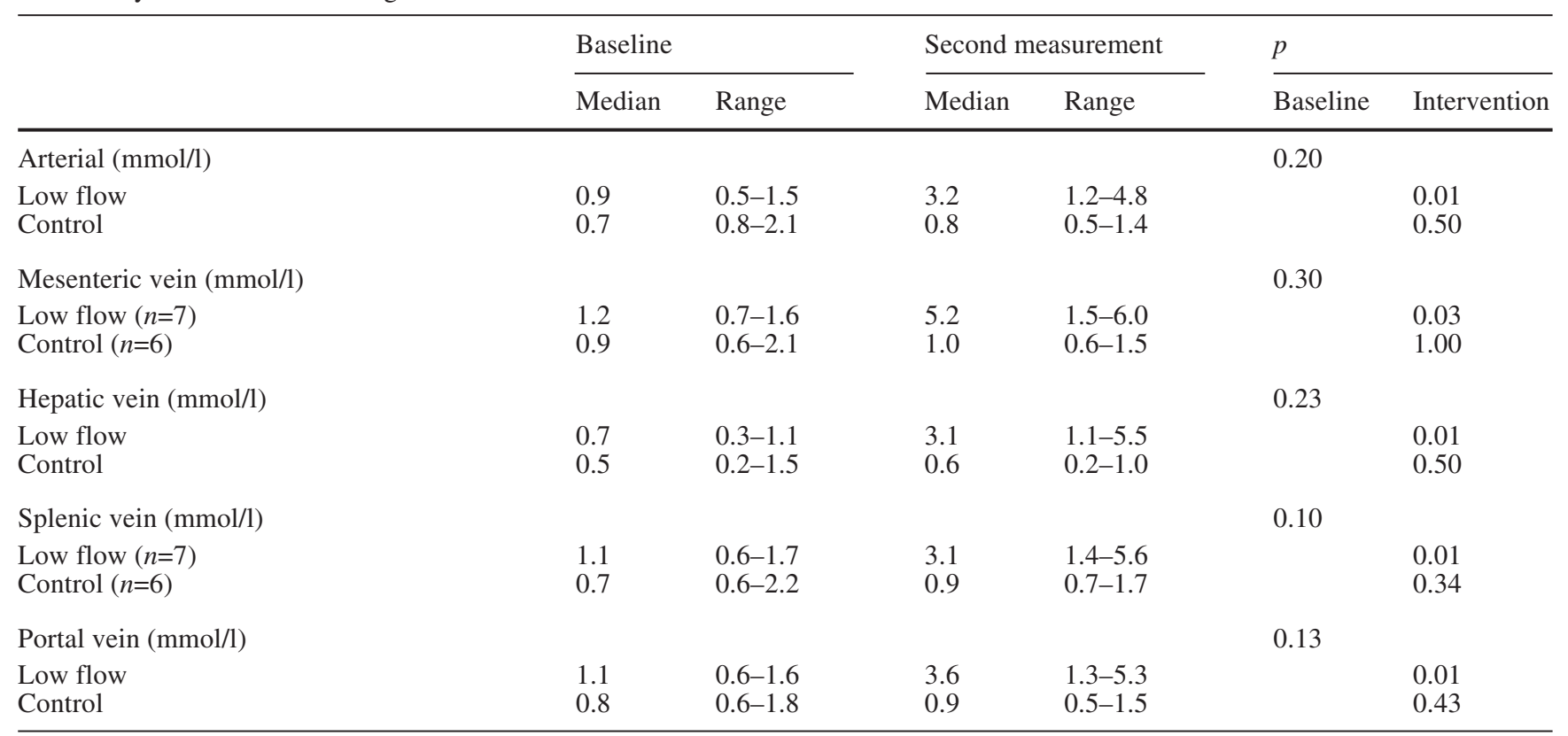


Table 4 Regional and mucosal $\mathrm{pCO}_{2}$ gradients and tonometry data

\begin{tabular}{|c|c|c|c|c|c|c|}
\hline & \multicolumn{2}{|l|}{ Baseline } & \multicolumn{2}{|c|}{ Second measurement } & \multicolumn{2}{|l|}{$p$} \\
\hline & Median & Range & Median & Range & Baseline & Intervention \\
\hline Low flow $(n=7)$ & 15 & $6-19$ & 28 & $8-54$ & & 0.04 \\
\hline Control $(n=6)$ & 11 & $8-16$ & 11 & $5-17$ & & 0.89 \\
\hline Hepatic $\mathrm{pCO}_{2}$ gradient $(\mathrm{mmHg})$ & & & & & 0.65 & \\
\hline Control & 10 & $8-13$ & 10 & $7-12$ & & 0.64 \\
\hline Splenic $\mathrm{pCO}_{2}$ gradient $(\mathrm{mmHg})$ & & & & & 0.61 & \\
\hline Low flow & 7 & $5-12$ & 15 & $8-31$ & & 0.01 \\
\hline Control & 8 & $3-14$ & 6 & $1-12$ & & 0.74 \\
\hline Portal $\mathrm{pCO}_{2}$ gradient $(\mathrm{mmHg})$ & & & & & 0.23 & \\
\hline Control & 36 & $14-79$ & 39 & $14-85$ & & 0.31 \\
\hline Jejunal tonometric-arterial $\mathrm{pCO}_{2}$ gradient $(\mathrm{mmHg})$ & & & & & 0.52 & \\
\hline Low flow & 9 & $1-24$ & 44 & $10-101$ & & 0.04 \\
\hline Control & 7 & $1-10$ & 6 & $2-10$ & & 1.00 \\
\hline
\end{tabular}

Table 5 Regional oxygen consumption and oxygen extraction rates

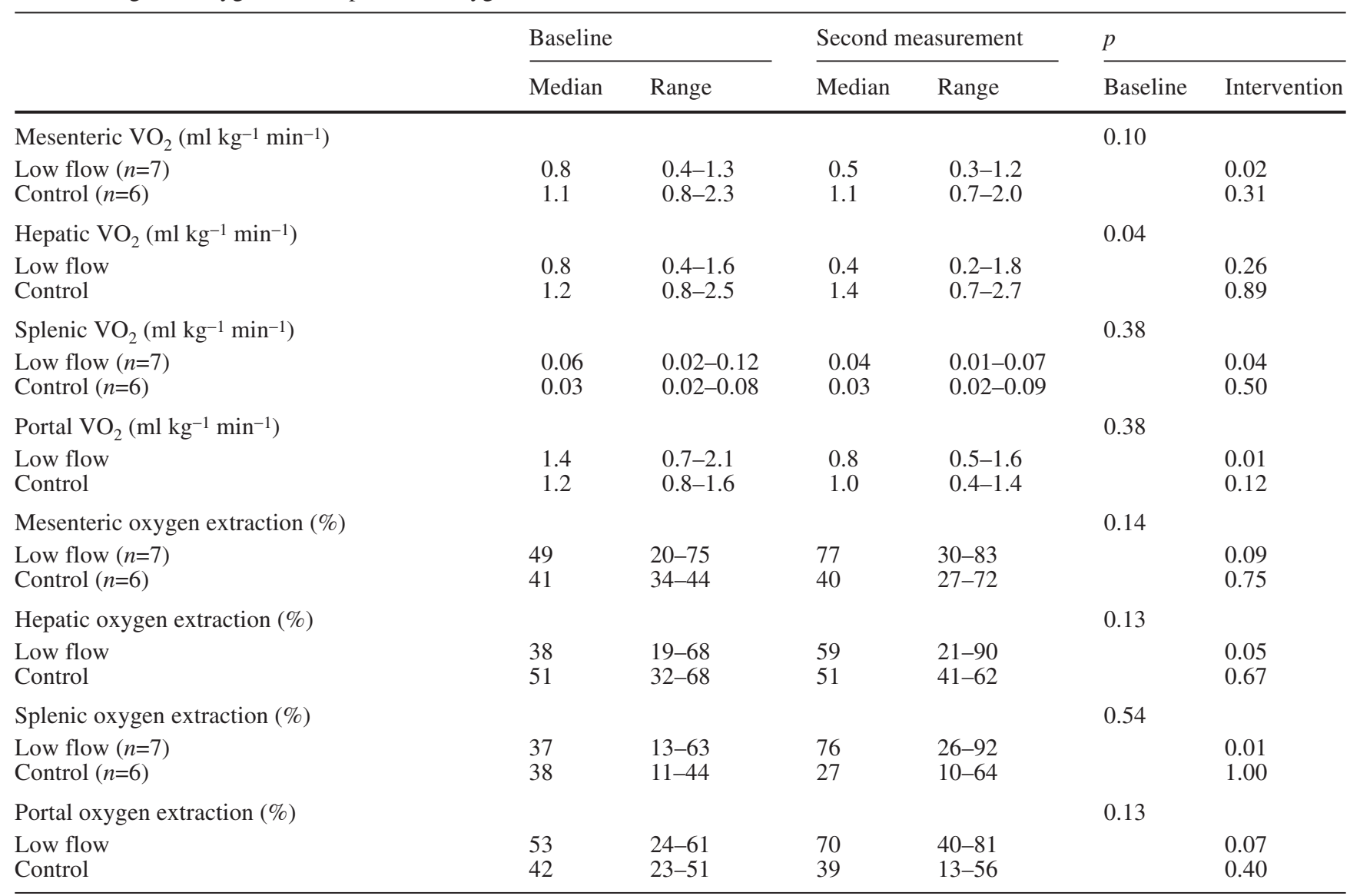



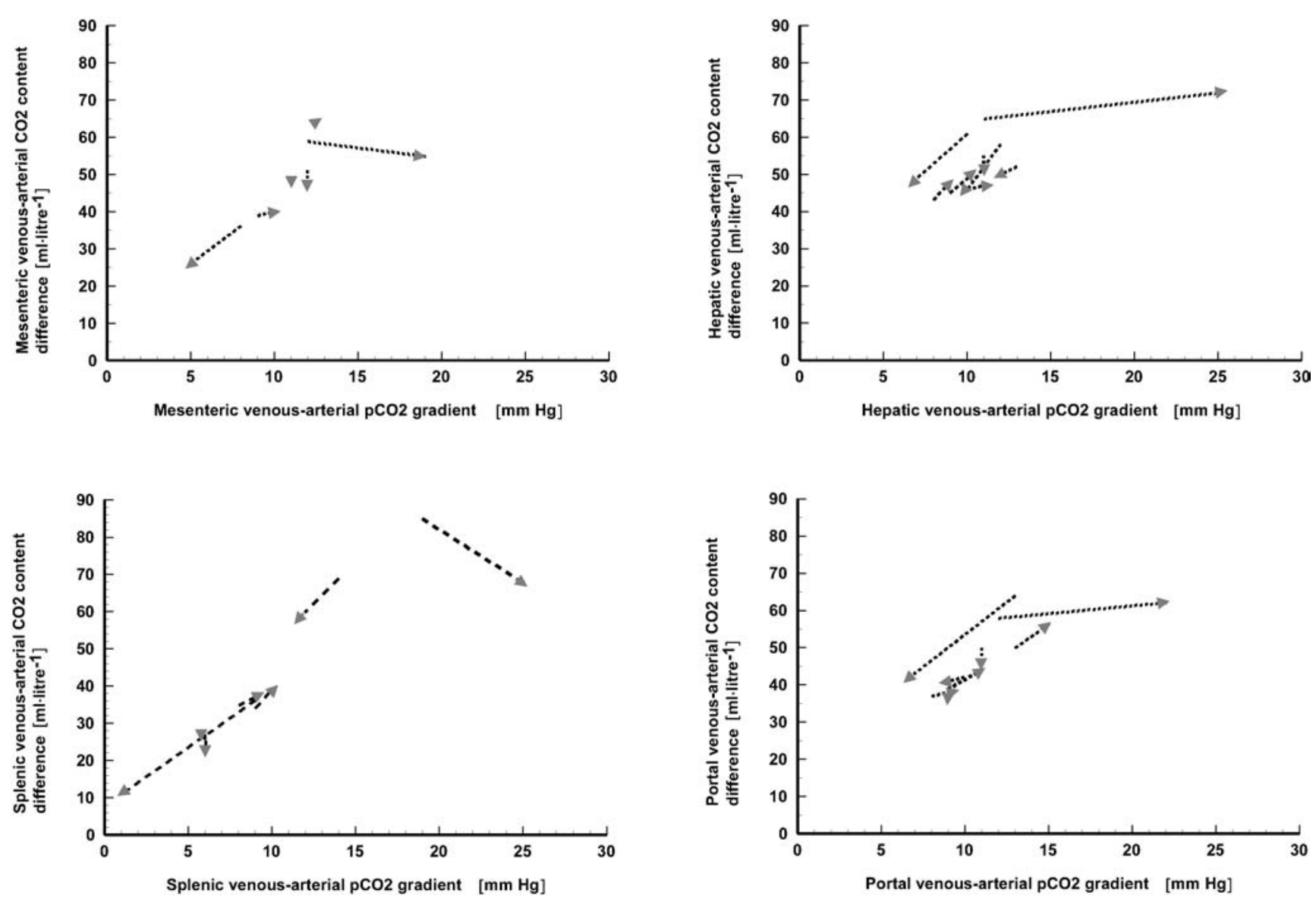

Fig. 2 Splenic, mesenteric, hepatic, and portal venous-arterial $\mathrm{pCO}_{2}$ gradient and venous-arterial $\mathrm{pCO}_{2}$ content difference

somewhat higher in control animals at baseline. Regional $\mathrm{VO}_{2}$ remained stable in control animals. In the low-flow group mesenteric, splenic and portal oxygen consumption was decreased, while only the increase in hepatic and splenic oxygen extraction rate reached statistical significance.

\section{Discussion}

The main findings were as follows: (a) In the low-flow group all regional flows decreased proportionally, no vascular bed was preferentially perfused, and the perfusion was not preferentially reduced to any vascular bed. (b) Low abdominal blood flow was associated with a substantial reduction in $\mathrm{O}_{2}$ consumption in several splanchnic tissues. (c) In most instances small changes in $\mathrm{pCO}_{2}$ gradients reflected the respective changes in $\mathrm{CO}_{2}$ content differences. (d) Despite major changes in oxygen extraction, hemoglobin, and temperature the $\mathrm{pCO}_{2}$ gradients reflected changes in corresponding regional blood flows in most of the cases (Fig. 3).

This study describes a new model for the assessment of hemodynamic and metabolic effects of low splanchnic blood flow. The model excludes to a great extent effects of hemodynamic and metabolic changes in other vascular beds. The slight increase in cardiac output and heart rate in the control group may reflect a systemic inflammatory reaction to surgery and indwelling catheters. The lack of such a circulatory response in the low-flow group may be explained by the slight reduction in left ventricular filling, as suggested by a reduction in pulmonary capillary occlusion pressures in these animals. Both a reduction in systemic vascular resistance due to hemodilution and the resulting reduction in blood viscosity as well as potential mechanic effects of the running roller pump may contribute $[33,34]$. Another effect of the extracorporeal circulation was a reduction in temperature [35, 36,37 , which we were not able to prevent completely by using warmed fluids and heating blankets. In future experiments an in-line blood heater can be integrated in the extracorporeal shunt system to prevent this problem.

Earlier studies have demonstrated an overproportional decrease in the perfusion of visceral organs in experimental circulatory shock $[5,6,7,8,9]$. It has been suggested that contraction of the splanchnic, and specifically the splenic vascular bed, helps to maintain central blood volume and cardiac output in hypovolemic states, 

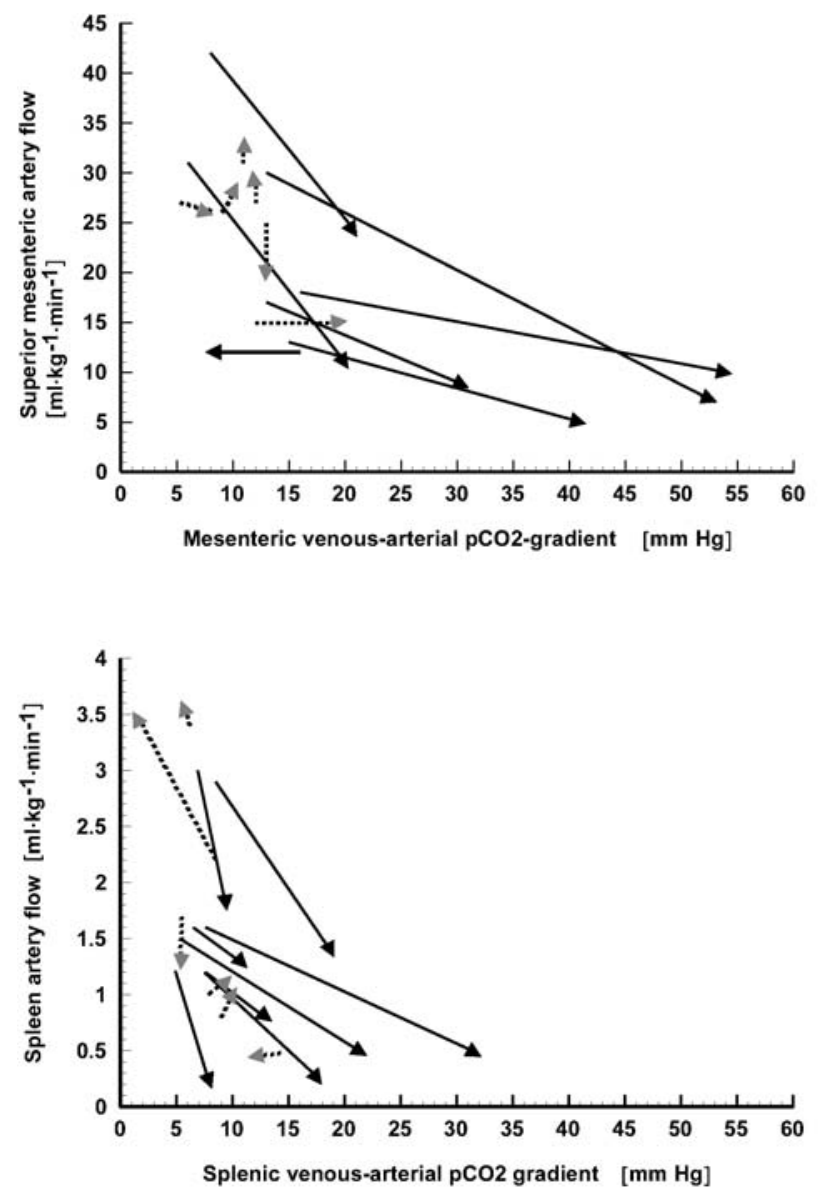

Fig. 3 Mesenteric venous-arterial $\mathrm{pCO}_{2}$ gradient and superior mesenteric artery flow, splenic venous-arterial $\mathrm{pCO}_{2}$ gradient and splenic artery flow, hepatic venous-arterial $\mathrm{pCO}_{2}$ gradient and total hepatic blood flow, and portal venous-arterial $\mathrm{pCO}_{2}$ gradient and portal venous flow

for instance, during fluid removal associated with hemodialysis [38]. In the present study all regional blood flows decreased in parallel by roughly $50 \%$ (Table 2); the more marked reduction in abdominal aortic flow may be explained by measuring errors due to turbulent blood flow. It is important to realize that in the experiments by Bailey and Bulkley and colleagues [7, 8, 9] low systemic blood flow was achieved by a combination of hemorrhage and cardiac tamponade. The authors combined hemorrhage and cardiac tamponade because they realized that prior hemorrhage sensitized the animals to subsequent tamponade. In our experiment hypovolemia was prevented, which could explain the discrepancies between our findings and those of their experiments.

The reduction in regional blood flows was associated with marked decreases in regional $\mathrm{O}_{2}$ consumption and increases in oxygen extraction rates in individual animals, especially in the low-flow group (Table 5). While
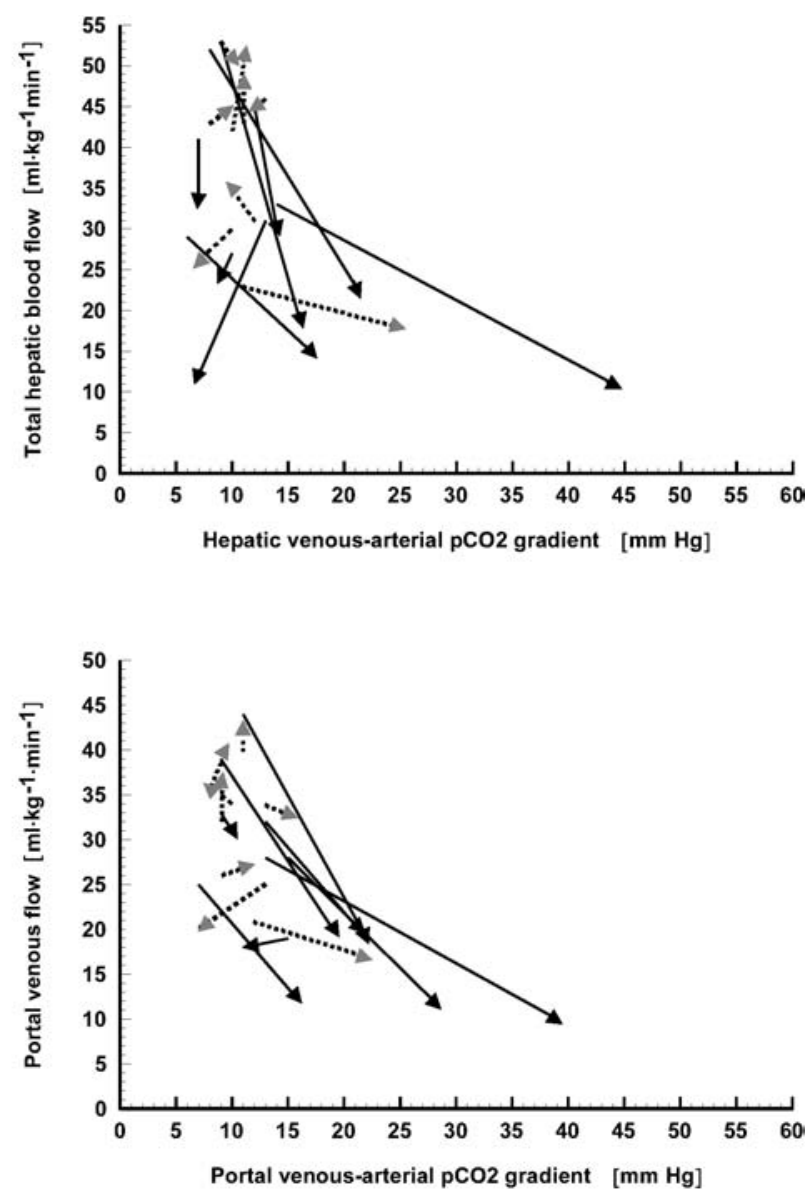

some of the changes may be due to mathematical coupling associated with the use of shared variables in the calculations [39], and others may be explained by associated falls in temperature, we believe that the reduction in regional metabolism in animals in the low-flow group is due to a transition to flow-dependent metabolism [40]. The rising blood lactate concentrations from the different splanchnic tissues (Table 3) support this assumption. Our results and those of others [41] also demonstrate that the flow/metabolism relationship is not uniform in different splanchnic vascular regions. On the other hand, in this experimental setting gastric and jejunal $\mathrm{pCO}_{2}$ gradients increased similarly, corresponding to a similar decrease in celiac trunk and superior mesenteric arterial blood flow. Accordingly, as far as our experimental design is comparable to a situation of low systemic blood flow in humans, it can be postulated that gastric tonometry detects substantial changes in mesenteric perfusion.

The rationale behind the use of $\mathrm{pCO}_{2}$ gradients as an estimate of related blood flow changes is the almost linear relationship between blood carbon dioxide content and $\mathrm{pCO}_{2}$, assuming unchanged oxygen saturation, hemoglobin, and $\mathrm{pH}$. Although our results demonstrate such a linear relationship in the group as a whole, in individual animals there was a dissociation between changes in 
$\mathrm{pCO}_{2}$ gradients and the respective $\mathrm{CO}_{2}$ content differences (Fig. 2). Several methods exist to calculate regional venous-arterial $\mathrm{CO}_{2}$ content differences [42, 43]. Unfortunately their accuracy is limited in low flow states. The method proposed by Giovannini et al. [31], for instance, may not be applied in situations with massive release of acid ions from anaerobic tissue metabolism into slowly flowing venous blood in shock states because of the discrepancy between $\mathrm{CO}_{2}$-binding properties of venous and arterial blood. Therefore calculation of regional venousarterial $\mathrm{CO}_{2}$ content differences and $\mathrm{CO}_{2}$ production is difficult. Major changes in (venous) oxygen saturation, hemoglobin, and the venous-arterial $\mathrm{pH}$ difference occurred in the present experiment, and such changes also occur during surgery and intensive care in patients [26]. Among these effects the Haldane effect is quantitatively the most important one. The Haldane effect describes the phenomenon of a leftward shift of the $\mathrm{CO}_{2}$ dissociation curve with decreasing oxygen saturation $[44,45]$. The Haldane effect plays an important role for the magnitude of changes in $\mathrm{pCO}_{2}$ gradients for a given change in blood flow as long as the oxygen extraction increases with decreasing blood flow, and hence the venous oxygen saturation decreases. In our experiment the mean Haldane effect on venous-arterial $\mathrm{pCO}_{2}$ gradients was relatively small $(4 \mathrm{mmHg})$ although maximal values of $10 \mathrm{mmHg}$ were calculated. These values correspond to $23-48 \%$ of the total $\mathrm{pCO}_{2}$ gradients. Despite this decreases in regional blood flows were almost always associated with corresponding increases in the respective $\mathrm{pCO}_{2}$ gradients. Errors in measurements of $\mathrm{pCO}_{2}$, hematocrit, and $\mathrm{pH}$ are further explanations for the exceptional discrepancies between changes in $\mathrm{CO}_{2}$ content and $\mathrm{pCO}_{2}$ differences. The present model produces regional ischemic hypoxia and obviously lacks the ability to limit the increasing $\mathrm{pCO}_{2}$ gradients associated with major $\mathrm{CO}_{2}$ stagnation. In models in which the oxygen content is decreased in the presence of maintained blood flow (hypoxic hypoxia [46, 47]), the Haldane effect would become a principal process in eliminating $\mathrm{CO}_{2}$.

Progressive anemia during the experiment is another potential confounding factor. During isovolemic anemia down to a hematocrit of $12 \%, \mathrm{CO}_{2}$ transport is maintained mainly by an increased blood flow and an augmented Haldane effect induced by the increased oxygen extraction [48]. Arterial, venous, and mucosal $\mathrm{pCO}_{2}$ are maintained $[48,49,50]$. In our experiment blood flow decreased, and anemia progressed at the same time. We believe that under these circumstances anaerobic metabolism develops earlier than reduction in blood flow without anemia. The combined effect of low blood flow, anaerobic $\mathrm{CO}_{2}$ production, and an augmented Haldane effect on the course of the $\mathrm{pCO}_{2}$ gradients is difficult to predict. Furthermore, changing body temperature in individual animals may also have had an impact on the relationship between metabolism and blood flow.
We conclude that this new experimental model allows a selective reduction in visceral blood flows to clinically relevant levels while systemic perfusion is maintained. The limitations are extensive surgery, difficulty in obtaining stable blood flow conditions and temperature, and substantial hemodilution. Under the experimental conditions, with prevention of hypovolemia, no preferential reduction or preservation of blood flows to the different visceral tissues occurred. In a setting of low blood flow, even with concomitant metabolic changes, and progressive anemia $\mathrm{pCO}_{2}$ gradients can be used for the assessment of blood flow changes.

\section{Appendix: calculation of the venous-arterial $\mathrm{CO}_{2}$-content difference}

Venous-arterial $\mathrm{CO}_{2}$-content difference was calculated using the method developed by Giovannini et al. [31]. Briefly, the concentration of $\mathrm{CO}_{2}$ in arterial blood is determined by the concentration of combined $\mathrm{CO}_{2}$ in plasma $\left(\mathrm{CaCO}_{2} \mathrm{p}\right)$ and red blood cells $\left(\mathrm{CaCO}_{2} \mathrm{r}\right)$, dissolved $\mathrm{CO}_{2}\left(\mathrm{CaCO}_{2} \mathrm{~d} \mathrm{ml} / 100 \mathrm{ml}\right.$ for all $)$, and hematocrit. $\mathrm{CaCO}_{2}$ $=\mathrm{CaCO}_{2}$ p. $\left[1-\mathrm{Hct} \times\left(1-\mathrm{CaCO}_{2} \mathrm{r} / \mathrm{CaCO}_{2} \mathrm{p}\right)\right]+\mathrm{CaCO}_{2} \mathrm{~d} . \mathrm{CaCO}_{2} \mathrm{p}$ is calculated from the arterial $\mathrm{pCO}_{2}$ and $\mathrm{pH}$ on the basis of the Henderson-Hasselbalch equation: $\mathrm{CaCO}_{2} \mathrm{p}=0.06868 \times$ $\left(\mathrm{PaCO}_{2}\right) \times\{10[1.04214 \times(\mathrm{pHa})-6.41036]\}$. The value of $\mathrm{ra}=\mathrm{CaCO}_{2} \mathrm{r} / \mathrm{CaCO}_{2} \mathrm{p}$ is obtained as a function of plasma $\mathrm{pH}$ and arterial $\mathrm{O}_{2}$ saturation and by using a concentration fraction of water in plasma and red blood cells of 0.938 and 0.720 , respectively: $\mathrm{ra}=2.5814-0.2640 \times$ (pHa)-[0.2203-0.0376 $\times(\mathrm{pHa})] \times\left(1-\mathrm{SaO}_{2}\right) . \mathrm{CaCO}_{2} \mathrm{~d}$ is finally calculated assuming a Bunsen coefficient for red blood cells $0.00947 \mathrm{ml} / 100 \mathrm{ml} \mathrm{mmHg}$ lower than that of plasma. $\mathrm{CaCO}_{2} \mathrm{~d}=\mathrm{PaCO}_{2} \times[0.06868-0.00947 \times(\mathrm{Hct})]$. Any increase in blood $\mathrm{CO}_{2}$ concentration related to the increase in $\mathrm{pCO}_{2}$ and to the simultaneous decrease in $\mathrm{SaO}_{2}$, which takes place when arterial blood becomes venous, is calculated by considering these two components separately and by using the mathematical model developed and described in detail by Giovannini et al. [31]. This model simulates the equilibration of whole blood at increasing $\mathrm{pCO}_{2}$ to determine the virtual values of combined $\mathrm{CO}_{2}$ concentration in plasma and of plasma $\mathrm{pH}$, resulting from the increase in $\mathrm{pCO}_{2}$ from arterial to venous value at constant $\mathrm{SaO}_{2}$. In a further step the increase in blood $\mathrm{CO}_{2}$ concentration that is related to the decrease in $\mathrm{O}_{2}$ saturation from arterial to venous value at constant $\mathrm{pCO}_{2}$ is then calculated. The total increment in $\mathrm{CO}_{2}$ concentration from arterial to venous blood is finally calculated from the sum of the two changes.

We compared previously the calculated and measured systemic venous-arterial $\mathrm{CO}_{2}$ content difference (measured as systemic arterial-venous $\mathrm{O}_{2}$ content difference multiplied by RQ obtained from indirect calorimetry [51]). The coefficient of correlation was $0.772(p<0.001)$. 
The mean of the calculated venous-arterial $\mathrm{CO}_{2}$ content difference was $3.52 \pm 0.95$, and the mean of the measured venous-arterial $\mathrm{CO}_{2}$ content difference was $3.97 \pm 1.06$. The difference between the means was therefore $0.44 \pm 0.69$, and the $95 \%$ confidence interval was -0.63 to -0.25 , and significantly different from zero $(p<0.001)$.
Although the standard deviation of the means was similar to the one reported by Giovannini et al. (0.69 vs. 0.59$)$, we found a bias which was not reported in their investigation. Since we were looking at changes in venous-arterial $\mathrm{CO}_{2}$ content difference rather than absolute values, this bias is unlikely to confound the results.

\section{References}

1. Marshall JC, Christou NV, Meakins JL (1993) The gastrointestinal tract. The "undrained abscess" of multiple organ failure. Ann Surg 218:111-119

2. Antonsson JB, Fiddian-Green RG (1991) The role of the gut in shock and multiple system organ failure. Eur J Surg 157:3-12

3. Knichwitz G, Van Aken H, Brussel T (1998) Gastrointestinal monitoring using measurement of intramucosa PCO2. Anesth Analg 87:134-142

4. Moore EE, Moore FA, Franciose RJ, Kim FJ, Biffl WL, Banerjee A (1994) The postischemic gut serves as a priming bed for circulating neutrophils that provoke multiple organ failure. J Trauma 37:881-887

5. Bulkley GB, Kvietys PR, Perry MA, Granger DN (1983) Effects of cardiac tamponade on colonic hemodynamics and oxygen uptake. Am J Physiol 244:G604-G612

6. Bulkley GB, Oshima A, Bailey RW (1986) Pathophysiology of hepatic ischemia in cardiogenic shock. Am J Surg 151:87-97

7. Bailey RW, Bulkley GB, Hamilton SR, Morris JB, Smith GW (1986) Pathogenesis of nonocclusive ischemic colitis. Ann Surg 203:590-599

8. Bailey RW, Bulkley GB, Hamilton SR, Morris JB, Haglund UH (1987) Protection of the small intestine from nonocclusive mesenteric ischemic injury due to cardiogenic shock. Am J Surg 153:108-116

9. Bailey RW, Bulkley GB, Hamilton SR, Morris JB, Haglund UH, Meilahn JE (1987) The fundamental hemodynamic mechanism underlying gastric "stress ulceration" in cardiogenic shock. Ann Surg 205:597-612

10. Hamilton-Davies C, Mythen MG, Salmon JB, Jacobson D, Shukla A, Webb AR (1997) Comparison of commonly used clinical indicators of hypovolaemia with gastrointestinal tonometry. Intensive Care Med 23:276-281

11. Heino A, Hartikainen J, Merasto ME, Koski EM, Alhava E, Takala J (1997) Systemic and regional effects of experimental gradual splanchnic ischemia. J Crit Care 12:92-98
12. Heino A, Hartikainen J, Merasto ME, Alhava E, Takala J (1998) Systemic and regional pCO2 gradients as markers of intestinal ischaemia. Intensive Care Med 24:599-604

13. Uusaro A, Ruokonen E, Takala J (1996) Splanchnic oxygen transport after cardiac surgery: evidence for inadequate tissue perfusion after stabilization of hemodynamics. Intensive Care Med 22:26-33

14. Zhang H, Vincent JL (1993) Arteriovenous differences in $\mathrm{PCO} 2$ and $\mathrm{pH}$ are good indicators of critical hypoperfusion. Am Rev Respir Dis 148:867-871

15. Ruokonen E, Soini HO, Parviainen I, Kosonen P, Takala J (1997) Venoarterial $\mathrm{CO} 2$ gradient after cardiac surgery: relation to systemic and regional perfusion and oxygen transport. Shock 8:335-340

16. Teboul JL, Graini L, Boujdaria R, Berton C, Richard C (1993) Cardiac index vs oxygen-derived parameters for rational use of dobutamine in patients with congestive heart failure. Chest 103:81-85

17. Vallet B, Teboul JL, Cain S, Curtis S (2000) Venoarterial CO (2) difference during regional ischemic or hypoxic hypoxia. J Appl Physiol 89:1317-1321

18. Fiddian-Green RG, Pittenger G, Whitehouse WM Jr (1982) Back-diffusion of $\mathrm{CO} 2$ and its influence on the intramural $\mathrm{pH}$ in gastric mucosa. J Surg Res 33:39-48

19. Brown SD, Gutierrez G (1996) Does gastric tonometry work? Yes. Crit Care Clin 12:569-585

20. Benjamin E, Oropello JM (1996) Does gastric tonometry work? No. Crit Care Clin 12:587-601

21. Russell JA (1997) Gastric tonometry: does it work? Intensive Care Med 23:3-6

22. Morgan TJ, Venkatesh B, Endre ZH (1997) Continuous measurement of gut luminal PCO2 in the rat: responses to transient episodes of graded aortic hypotension. Crit Care Med 25:1575-1578

23. Morgan TJ, Venkatesh B, Endre ZH (1999) Accuracy of intramucosal pH calculated from arterial bicarbonate and the Henderson-Hasselbalch equation: assessment using simulated ischemia. Crit Care Med 27:2495-2499
24. Uusaro A, Ruokonen E, Takala J (1995) Gastric mucosal pH does not reflect changes in splanchnic blood flow after cardiac surgery. Br J Anaesth 74:149-154

25. Schlichtig R, Bowles SA (1994) Distinguishing between aerobic and anaerobic appearance of dissolved $\mathrm{CO} 2$ in intestine during low flow. J Appl Physiol 76:2443-2451

26. Jakob SM, Kosonen P, Ruokonen E, Parviainen I, Takala J (1999) The Haldane effect-an alternative explanation for increasing gastric mucosal $\mathrm{PCO} 2$ gradients? Br J Anaesth 83:740-746

27. Tenhunen JJ, Kosunen H, Alhava E, Tuomisto L, Takala JA (1999) Intestinal luminal microdialysis: a new approach to assess gut mucosal ischemia. Anesthesiology 91:1807-1815

28. Jakob SM, Merasto-Minkkinen M, Tenhunen JJ, Heino A, Alhava E, Takala J (2000) Prevention of systemic hyperlactatemia during splanchnic ischemia. Shock 14:123-127

29. Lundell A, Bergqvist D, Mattsson E, Nilsson B (1993) Volume blood flow measurements with a transit time flowmeter: an in vivo and in vitro variability and validation study. Clin Physiol 13:547-557

30. Hartman JC, Olszanski DA, Hullinger TG, Brunden MN (1994) In vivo validation of a transit-time ultrasonic volume flow meter. J Pharmacol Toxicol Methods 31:153-160

31. Giovannini I, Chiarla C, Boldrini G, Castagneto M (1993) Calculation of venoarterial $\mathrm{CO} 2$ concentration difference. J Appl Physiol 74:959-964

32. Giovannini I, Chiarla C, Boldrini G, Terzi R (1999) Quantitative assessment of changes in blood CO (2) tension mediated by the Haldane effect. J Appl Physiol 87:862-866

33. Hardesty RL, Baker LD, Gall DA, Bahnson HT (1969) Systemic resistance during cardiopulmonary bypass. Surg Forum 20:185-188

34. Weiland AP, Walker WE (1986) Physiologic principles and clinical sequelae of cardiopulmonary bypass. Heart Lung 15:34-39 
35. Pellegrini A, Respighi E, Panzeri E (1967) [Extracorporeal circulationhypothermia and the problem of hemodilution]. Minerva Med 58:2149-2151

36. Moon YS, Ohtsubo S, Gomez MR, Moon JK, Nose Y (1996) Comparison of centrifugal and roller pump hemolysis rates at low flow. Artif Organs 20:579-581

37. Mueller XM, Tevaearai HT, Jegger D, Tucker O, von Segesser LK (2001) Hemolysis and hematology profile during perfusion: inter-species comparison. Int J Artif Organs 24:89-94

38. Yu AW, Nawab ZM, Barnes WE, Lai KN, Ing TS, Daugirdas JT (1997) Splanchnic erythrocyte content decreases during hemodialysis: a new compensatory mechanism for hypovolemia. Kidney Int 51:1986-1990

39. Archie JP Jr (1981) Mathematic coupling of data: a common source of error. Ann Surg 193:296-303

40. Pastor CM (2000) Hepatic and splanchnic oxygen consumption during acute hypoxemic hypoxia in anesthetized pigs. Crit Care Med 28:765-773
41. Rendig SV, Chahal PS, Longhurst JC (1997) Cardiovascular reflex responses to ischemia during occlusion of celiac and/or superior mesenteric arteries. Am J Physiol 272:H791-H796

42. Loeppky JA, Fletcher ER, Roach RC, Luft UC (1993) Relationship between whole blood base excess and $\mathrm{CO} 2$ content in vivo. Respir Physiol 94:109-120

43. Douglas AR, Jones NL, Reed JW (1988) Calculation of whole blood CO2 content. J Appl Physiol 65:473-477

44. Siggaard-Andersen O, Garby L (1973) The Bohr effect and the Haldane effect. Scand J Clin Lab Invest 31:1-8

45. Christiansen J, Douglas CG, Haldane JS (1914) The absorption and dissociation of carbon dioxide by human blood. J Physiol 48:244

46. Dubin A, Murias G, Estenssoro E, Canales H, Badie J, Pozo M, Sottile JP, Baran M, Palizas F, Laporte M (2002) Intramucosal-arterial PCO2 gap fails to reflect intestinal dysoxia in hypoxic hypoxia. Crit Care 6:514-520

47. Neviere R, Chagnon JL, Teboul JL, Vallet B, Wattel F (2002) Small intestine intramucosal PCO (2) and microvascular blood flow during hypoxic and ischemic hypoxia. Crit Care Med 30:379-384
48. Deem S, Alberts MK, Bishop MJ, Bidani A, Swenson ER (1997) CO2 transport in normovolemic anemia: complete compensation and stability of blood CO2 tensions. J Appl Physiol 83:240-246

49. Dubin A, Estenssoro E, Murias G, Canales H, Sottile P, Badie J, Baran M, Palizas F, Laporte M, Rivas DM (2001) Effects of hemorrhage on gastrointestinal oxygenation. Intensive Care Med 27:1931-1936

50. Vallet B (2002) Influence of flow on mucosal-to-arterial carbon dioxide difference. Crit Care 6:463-464

51. Jakob SM, Kosonen P, Ruokonen E, Parviainen I, Takala J (1999) The Haldane effect - an alternative explanation for increasing gastric mucosal PCO2 gradients? Br J Anaesth 83:740-746 